\title{
Psychological problems of patients with scoliosis who utilize the Cheneau's brace
}

\author{
FA Levitskiy*, NS Yaroslavska, NL Litvinova, EK Ryhlevskiy, VA Bebeshko, \\ AV Plyatsek and NA Velikiy
}

Address: Pediatric Orthopaedics/Trauma, Central Ukranian Pediatric Hospital, Ukraine

* Corresponding author

from $5^{\text {th }}$ International Conference on Conservative Management of Spinal Deformities

Athens, Greece. 3-5 April 2008

Published: 15 January 2009

Scoliosis 2009, 4(Suppl I):O64 doi:I0.1 I86/I748-7|6I-4-SI-O64

This abstract is available from: http://www.scoliosisjournal.com/content/4/SI/O64

(C) 2009 Levitskiy et al; licensee BioMed Central Ltd.

\section{Background}

An important element in treatment of scoliosis is the evaluation and correction of the patient's psychological status. Changes in their usual lifestyle as well as the daily need to use the brace are the additional negative factors which affect a child. The psychological disorders which evolve may create limitations in personal relationships.

\section{Methods}

Clinical cases of 260 patients aged 10-16 treated by Cheneau's brace were included.

To evaluate the psychological and emotional state the following were implemented: Lusher colour test, evaluation of light perception in dreams, psychological image test, observance of the level of neurosis, Spilberg's questionnaire for parents and children, vegetative test by Hildenbrand and Kerdo as well as an evaluation of the general somatic state.

\section{Results}

All children had problems adapting to the brace. This period was characterized by negative emotional conditions, such as dream disturbance, increased irritability, negation, anxiety, fears, and change of mood. Internal disharmony connected with a new life in the brace was seen among girls aged 13-16. Approximately $30 \%$ of the patients experienced neurosis due to personal discomfort, to process expectations and to the potential for a negative treatment result. Psychological condition of $16.2 \%$ of patients depended on their relatives' attitude to the process and result of treatment.

\section{Conclusion}

Monitoring of the emotional response to treatment for scoliosis by the Cheneau's brace will improve the quality of the treatment. In addition, incorporating a psychologist's assistance in the management of these emotional responses may lead to improved quality of treatment.

\section{References}

I. Lindeman M, Behm K: Cognitive strategies and self-esteem as predictors of brace-wear noncompliance in patients with idiopathic scoliosis and kyphosis. I Pediatr Orthop 1999, 19(4):493-9. 